\title{
Combined Foliar and Soil Selenium Fertilizer Improves Selenium Transport in Oats and the Diversity of the Bacterial Community in Rhizosphere Soil
}

\section{Junhui Li}

Shanxi Agricultural University College of Agriculture

\section{Wenping Yang}

College of Life Sciences, North China University of Science and Technology

\section{Anna Guo}

Shanxi Agricultural University College of Agriculture

\section{Sheng Yang}

Shanxi Agricultural University College of Agriculture

Jie Chen

Shanxi Agricultural University College of Agriculture

\section{Yuejing Qiao}

Shanxi Agricultural University College of Agriculture

\section{Sumera Anwar}

Institute of Molecular Biology and Biotechnology, The University of Lahore

\section{Kai Wang}

Shanxi Agricultural University College of Agriculture

\section{Zhenping Yang ( $\nabla$ yangzhenping340@163.com )}

Shanxi Agricultural University

\section{Zhiqiang Gao}

Shanxi Agricultural University College of Agriculture

\section{Jianwu Wang}

Shanxi Institute of Geological Survey

\section{Research Article}

Keywords: Se fertilizer, Se content, oat, bacterial community, high-throughput sequencing

Posted Date: April 13th, 2021

DOI: https://doi.org/10.21203/rs.3.rs-385095/v1

License: (9) This work is licensed under a Creative Commons Attribution 4.0 International License. Read Full License

Version of Record: A version of this preprint was published at Environmental Science and Pollution Research on July 26th, 2021. See the published version at https://doi.org/10.1007/s11356-021-15439-4. 


\section{Abstract}

Reasonable application of selenium (Se) fertilizer is beneficial for improving Se contents in grains and can affect soil ecology. No study has compared Se fertilizer application methods on biofortification, yield, and soil bacterial community. This study investigated the effects of topsoil (T), foliar (S), and soil+foliar (TS) application of Se fertilizer on oats. TS treatment significantly increased oat yield compared with the control and S. The Se content in grains was increased in the order of TS > S $>$ T. T and TS increased the nutrients, soil organic matter, activities of urease, alkaline phosphatase, and sucrose, as well as the diversity and abundance of soil bacterial communities. According to PCA analysis, TS and T increased the relative abundance of bacteria involved in the decomposition of organic matter, such as Proteobacteria, Chloroflexi, and Bacteroidetes, while reduced Granulicella, Bacillus, Raoultella, Lactococcus, Klebsiella, and Pseudomonas. Furthermore, TS significantly increased the relative abundance of Aciditeromonas, Gemmatimonas, Geobacter, and Thiobacter. While, T significantly increased the abundance of Lysobacter, Holophaga, Candidatus-Koribacter, Povalibacter, and Pyrinomonas. S did not significantly change the bacterial communities. The redundancy analysis revealed that soil nutrients and enzyme activities were positively correlated with the abundance of Actinobacteria, Acidobacteria, Gemmatimonadetes, Bacteroidetes, Planctomycetes, and Chloroflexi, but negatively correlated with the abundance of Proteobacteria and Firmicutes. Thus, a combined application of foliar and soil Se proved most conducive for achieving higher yield, grain Se content, and improving bacterial community structure and functional gene expression in rhizosphere soil.

\section{Introduction}

Oats (Avena sativa L.) ranks sixth in the world among cereal crops according to the planting area following wheat, corn, rice, barley, and sorghum. Oats are rich in nutrients, such as fat, protein, vitamins, and fiber. At the same time, oats have important medical value and health effects and play important roles in preventing and treating hyperlipidemia and controlling obesity. Owing to its high nutritious values oat-based food and feed uses are gaining increasing consideration at the Loess Plateau of China.

Selenium (Se) is a trace element necessary for the human body (Brown \& Arthur 2001), and its deficiency can cause various diseases (Arroyo et al. 2015; Kieliszek \& Blazejak 2013). In China, Keshan and Keshin-Beck diseases become prevalent due to Se deficiency, for instance, the Keshan disease becomes common in the Tibetan Plateau and Heilongjiang province (Ye at al. 2020). The distribution of Se in the soil is highly uneven and site-specific (Banuelos et al. 2015). Approximately 51\% area of China is Se deficient (Dinh et al. 2018). An estimated 15\% of the global population (500-1100 million people) have Sedeficiency problems (Wang et al. 2017). Most of the Se in the human body is derived from plants which absorb Se from their external environment (Jozwiak \& Politycka 2019).

In some soil the bioavailability of Se is low and Se also forms stable complexes with clay or reacts with hydrous oxides to form complexes of low solubility and availability to plants. The application of Se fertilizer has proved to be a safe, low-cost, efficient, and convenient method to produce Se-rich plants (Chen et al. 2002). The soil and foliar application of Se fertilizers not only significantly increase the content of Se in crop grains but also increase yield (Escalante-Valdez et al. 2019; Lara et al. 2019; Ligowe et al. 2020; Reis et al. 2020). Foliar application of Se can be quickly absorbed by the leaf surface and efficiently transported to the grains to improve the utilization of Se (Zhang et al. 2019). While applying Se to the soil can increase soil enzyme activity and promote N, P, and C nutrients in the soil ecosystem cycle (Shi et al. 2018). The Se enrichment effect of these two Se application methods has been confirmed in many crops, such as corn (Longchamp et al. 2015), wheat (Manojlovic et al. 2019), rice (Fang et al. 2008), potato (Golubkina \& Skriabin 2010), and rape (Ding et al. 2017).

Soil microorganisms are an important part of the soil ecosystem and play a vital role in the process of material conversion, and energy flow in ecosystems (Palomo et al. 2016; Talbot et al. 2013). In the plant rhizosphere, microorganisms significantly affect the bioavailability of mineral elements in the soil-plant system and produce a healthy micro-ecological environment for the growth of the plant (Mendes et al. 2011; Nacke et al. 2017). The function of the microbial community is determined by the structure and diversity of the microbial community (Bakker et al. 2015). Any factors that affect the rhizosphere soil microbial community will affect the function of the community and the growth of plants. Studies have shown that micronutrients have 
an important effect on soil microbial community structure. Song et al (2020) showed that the presence of $\mathrm{Cd}, \mathrm{Cu}$, and $\mathrm{Zn}$, and micronutrients account for $30 \%$ of the change in microbial community structure in the soil. The richness and diversity of soil bacterial communities were significantly reduced at a high concentration of Cu or Zn (Golebiewski et al. 2014). The appropriate concentration of $\mathrm{Fe}, \mathrm{Mn}, \mathrm{Cu}$, and $\mathrm{Zn}$ can improve the soil bacterial community by promoting the diversity of probiotics (Paenibacillus polymyxa, Bacillus amyloliquefaciens, Bacillus mycoides, and Lysinibacillus) and improve the disease prevention ability of crops.

Variations in soil micronutrients can lead to change the soil physical and chemical properties, such as $\mathrm{pH}$, carbon, nitrogen, and the activity of soil enzymes which also influence the plant physiology and the composition and relative abundance of rhizosphere microorganisms (Lareen et al. 2016; Liu et al. 2019). Selenium could influence soil bacterial communities, and conversely, microbial activity can alter Se bioavailability and distribution (Rosenfeld et al. 2018). However, at present, there is very little research on the effects of selenium on soil bacteria and therefore, further studies are needed to confirm the effectiveness of different selenium biofertilization strategies under field conditions by elucidating the main mechanisms of Se uptake by plants and the response of soil bacterial communities to Se fertilizer.

Based on previous studies, we hypothesized that selenium fertilizer would have significant effects on oat growth and rhizosphere soil properties, enzyme activities, and microbial diversity. Therefore, the purpose of this study was to: (1) investigate the effects of selenium fertilizer on soil properties, and soil enzyme activities; (2) to compare the responses of bacterial diversity and community composition to selenium application; and (3) to evaluate the response of selenium content and yield of oats to selenium application.

\section{Materials And Methods}

\subsection{Study area}

The experiment was conducted from June to October 2017 in Haijiayao Village, Guanjiabao Township, Zuoyun County, Datong City, Shanxi Province. Zuoyun County is located in the northernmost part of Shanxi Province $\left(39^{\circ} 44 \rrbracket-44^{\circ} 15 \rrbracket N, 112^{\circ} 34 \rrbracket-\right.$ $\left.112^{\circ} 59 \otimes \mathrm{E}\right)$. It belongs to the Loess hilly region and has a typical, temperate, semi-arid continental climate with an average annual temperature of $5^{\circ} \mathrm{C}$, annual rainfall of $430 \mathrm{~mm}$, and a frost-free period of $105 \mathrm{~d}$. The soil is light chestnut type. The $0-$ $20 \mathrm{~cm}$ layer has $9.93 \mathrm{~g} \mathrm{~kg}^{-1}$ organic matter, $0.746 \mathrm{~g} \mathrm{~kg}^{-1}$ total nitrogen, $0.51 \mathrm{~g} \mathrm{~kg}^{-1}$ total phosphorus, $38.62 \mathrm{mg} \mathrm{kg}^{-1}$ alkaline nitrogen, $12.50 \mathrm{mg} \mathrm{kg}^{-1}$ available phosphorus, $92.41 \mathrm{mg} \mathrm{kg}^{-1}$ available potassium, a pH of 8.68 , and $356.23 \mu \mathrm{g} \mathrm{kg}$ 1 Se.

\subsection{Oat variety and Se fertilizers}

The seeds of oat (Avena sativa L.) variety 'Jinyan 21' were provided by Youyu Agricultural Experimental Station of the Shanxi Academy of Agricultural Sciences. An organic Se fertilizer (Se content $36.4 \mathrm{mg} \mathrm{kg}^{-1}$, NPK nutrient content $\geq 5 \%$, organic matter content $\geq 45 \%$ ) was used as a topdressing. Additionally, a Se-enriched composite synergist aqueous solution containing $8 \mathrm{mg} \mathrm{mL}^{-1}$ Se (Yifeng Selenium-Rich Agricultural Products R \& D Co., Ltd. Taiyuan, Shanxi Province) was used as a foliar spray (diluted 100 times before the use). Both Se fertilizers contained Se in the form of selenite $\left(\mathrm{Se}^{4+}\right)$.

\subsection{Experimental design and treatments}

The treatments were arranged in a randomized complete blocks design. The four Se application treatments were: topdressing of $1.20 \mathrm{mg} \mathrm{m}^{-2}$ Se fertilizer at the booting stage (T); foliar spraying of $1.20 \mathrm{mg} \mathrm{m}^{-2}$ Se fertilizer at the flowering stage (S); both topdressing of $1.20 \mathrm{mg} \mathrm{m}^{-2}$ Se fertilizer at the booting stage and foliar spraying of $1.20 \mathrm{mg} \mathrm{m}^{-2}$ Se fertilizer at the flowering stage (TS); and no Se fertilizer as a control (CK). Se fertilizer is provided by Yifeng Selenium-Rich Agricultural Products R \& D Co., Ltd, and the application amount is the reasonable application amount obtained from the company's longterm practice in China. Each treatment was repeated three times, with a total of 12 plots. Each plot was $100 \mathrm{~m}^{2}$. The seeds of oat were sown on June 30, 2017. Before sowing, the soil was prepared by applying $6 \mathrm{~kg}$ of NPK fertilizer $\left(\mathrm{N}: \mathrm{P}_{2} \mathrm{O}_{5}: \mathrm{K}_{2} \mathrm{O}=\right.$ 
18:18:18, total nutrient content 54\%, organic matter content $\geq 45 \%$, Shanxi Tianji Coal Chemical Group Co., Ltd.) per plot. Seeds were sown using mechanized drilling. Row spacing was $20 \mathrm{~cm}$, with $1.2 \mathrm{~kg}$ of seeds sown per plot. Other field management measures, such as irrigation and weeding, were carried out according to the common practice in the region.

\subsection{Sample collection and processing}

Soil and plant samples were collected $1 \mathrm{~d}$ before oat harvesting. Three sampling points were randomly selected from each plot from which 10 plants were dug out carefully along with soil from a $20 \mathrm{~cm}$ radius around each plant. The rhizosphere soil was removed from the roots and roots were gently rinsed with clean water. Each plant was divided into root, stem, leaves, and ears. Then, the plants were dried in the oven at $65^{\circ} \mathrm{C}$ until the weight was constant and ground into a powder with an electric grinder (FZ102, Shanghai, China). The ground powder was passed through a $0.15 \mathrm{~mm}$ sieve and then sealed in Ziplock bags for analysis of total Se content. Similarly, $100 \mathrm{~g}$ of oat grains were ground into flour using an electric grinder (HCP 100, Zhejiang, China), pass through a $0.15 \mathrm{~mm}$ sieve, and sealed in a Ziploc bag for analysis of total Se content. Bulk soil samples were collected adjacent to excavated plants from the depth of 0-20 cm with a sterilized spiral drill having $8 \mathrm{~cm}$ diameter. The plant roots were removed by hand and rhizosphere and bulk soil samples were passed through a sieve $(2 \mathrm{~mm})$ and then divided into two parts. One part was placed in a refrigerator at $4^{\circ} \mathrm{C}$ for soil nutrient determination, and the other part was stored in liquid nitrogen at $-80^{\circ} \mathrm{C}$ for soil microbial analyses.

\subsection{Plant and soil analyses}

\subsubsection{Determination of yield components, and plant and soil nutrients}

Plant height, total spike number, yield, and 1000-grain weight were determined according to conventional methods. A mixture of $\mathrm{HNO}_{3}-\mathrm{H}_{2} \mathrm{O}_{2}$ ( $\mathrm{v} / \mathrm{v}$ ratio of 4:1) was used to digest the preserved plant and flour samples $(100 \mathrm{mg})$ in the digester reaction system (LWY84B, China). Then, the content of Se was determined using microwave digestion-inductively coupled plasma mass spectrometry (ICP-MS).

Conventional methods were used to determine nutrients and organic content in soil (Bell et al. 2005). The organic matter content was determined using the potassium dichromate external heating method; the nitrogen content was determined using the alkali hydrolysis diffusion method; the available phosphorus content was determined in a $0.5 \mathrm{~mol} \mathrm{~L}^{-1} \mathrm{NaHCO}_{3}$ extraction using the leaching-molybdenum antimony anti-colorimetric method; the available potassium content was determined in a 1.0 mol L-1 $\mathrm{NH}_{4} \mathrm{OAc}$ extraction using the leaching-flame photometric method. Soil urease activity was determined using the indophenol colorimetric method, soil sucrose activity was determined using the 3,5-dinitrosalicylic acid colorimetric method, and soil alkaline phosphatase activity was determined using the p-nitrophenyl phosphate colorimetric method (Guan 1986).

\subsubsection{Conversion rate of exogenous Se}

The conversion rate of exogenous Se was calculated using the following equation:

$$
R=\frac{C_{i-} C_{0}}{C E_{i}} \times 100 \%
$$

1

where, $R$ : conversion rate, $C_{\mathrm{i}}$ : Se content in Se treated plants, $C_{0}$ : Se content of control plants, $C E_{\mathrm{i}}$ : application amount of exogenous Se.

The rate of increase was calculated using the following equation:

$$
N=\frac{A_{i-} B_{i}}{B_{i}} \times 100 \%
$$


where, $N$ : increase rate, $A_{i}$ : Se content in Se treated plant organs, $B_{i}$ : Se content in control oat plant organs.

\subsubsection{Extraction and sequencing of soil genomic DNA}

FastDNA SPIN kits (MP Biomedical, Santa Ana, CA, USA) were used to extract total soil DNA, and then DNA concentration and purity were determined using a NealDel-ND1000 spectrophotometer (Thermo Fisher Scientific, Waltham, MA, USA) and agarose gel electrophoresis.

The 16S rRNA V4 region of the extracted genomic DNA was amplified using the general primer sequences: 520F (AYTGGGYDTAAAGNG), and 802R (TACNVGGGTATCTAATCC). The polymerase chain reaction (PCR) conditions were as follows: initial denaturation at $98^{\circ} \mathrm{C}$ for $2 \mathrm{~min}$; followed by 25 cycles of denaturation at $98^{\circ} \mathrm{C}$ for $15 \mathrm{~s}$, annealing at $55^{\circ} \mathrm{C}$ for 30 $\mathrm{s}$, and extension at $72^{\circ} \mathrm{C}$ for $30 \mathrm{~s}$; and a final extension at $72^{\circ} \mathrm{C}$ for $5 \mathrm{~min}$. PCR products were then stored at $4^{\circ} \mathrm{C}$. PCR products were purified using an Agencourt AMPure Beads kit (Beckman Coulter, Indianapolis, IN, USA), and quantified using a PicoGreen dsDNA assay kit (Invitrogen, Carlsbad, CA, USA). The samples were entrusted to Shanghai Passino Biotechnology Co., Ltd. for sequencing and analysis using the Illumina MiSeq high-throughput sequencing technology platform.

\subsubsection{Optimized processing of sequencing data}

Quality filtering and merging of paired-end sequences were performed using QIIME (version 1.9.0, //qiime.org/). Data filtering was conducted following the method of Feng et al. (2009). First, the sequence of the 5 -terminal primers was removed using a mismatch base number $>1$. Then, sequences containing Ns (fuzzy bases) were removed. Finally, sequences containing $>8$ consecutive, identical bases, and sequences with a length $\leq 150 \mathrm{bp}$ were removed. The UCHIME method in MOTHUR (version 1.31.2, http://www.mothur.org/) was used to remove chimera sequences and to obtain a high-quality sequence that was used for subsequent analysis.

\subsubsection{OTU cluster analysis and annotation}

The UCLUST method in QIIME was used to cluster high-quality sequences with a sequence similarity of $97 \%$. The longest sequence in each category was selected as the representative sequence. The BLAST method in QIIME was used to obtain taxonomic information for each OTU using the Greengenes database (release 13.8, http://greengenes.secondgenome.com/). Then, OTUs with an abundance of less than $0.001 \%$ of the total number of sequences were removed to obtain a simplified OTU table for subsequent analysis.

\subsubsection{PICRUSt function prediction}

Bacterial functions and metabolic pathways were predicted using PICRUSt (Muller et al. 2002); the closed OTU table obtained from QIIME was compared to the KEGG database to determine different bacterial community functions.

\subsection{Calculations and statistical analysis}

The Single command in MOTHUR was used to calculate the Chao1, ACE, Simpson, and Shannon diversity indices for soil bacteria using the OTU table obtained from QIIME (Schloss et al. 2011; Schloss \& Handelsman 2005). Beta diversity analysis was performed to investigate the structural variation in microbial communities across samples using UniFrac distance metrics (Lozupone \& Knight 2005; Lozupone et al. 2007). Principal component analysis (PCA) was conducted based on the specieslevel compositional profiles (Ramette 2007). A UPGMA cluster analysis was performed in QIIME with a weighted UniFrac distance matrix, and then R packages (v3.2.0) were used for visualization. Microsoft Excel 2003 was used for basic calculations; Origin (2019) was used to construct charts of the taxonomic composition and differences among communities at various levels. One-way analysis of variance (ANOVA) was performed using SAS 9.4 with a significance level of $P<0.05$.

CANOCO 4.5 was used to perform a redundancy analysis (RDA) of soil chemical properties, and bacterial community structure and diversity. 


\section{Results}

\subsection{Effects of Se fertilizer application on yield components of oats}

The topdressing of Se fertilizer at booting (T) and foliar spray at the flowering stage (S) has no significant effect on the plant height and the total number of spikes per unit area (Table 1). Compared with the control, the 1000-grain weight and grain yield were significantly influenced by Se. The topsoil application of Se (T), foliar spray of Se (S), and their combination (TS) showed a $12 \%, 9 \%$, and $18 \%$ increase in 1000-grain weight. S showed a non-significant effect on 1000-grain weight. The grain yield was significantly increased by TS, whereas T and S showed a non-significant increase. Thus, the maximum 1000-grain weight and grain yield were observed in TS.

Table 1

Effects of Selenium Fertilizer Application on Economic Characters of Oats

\begin{tabular}{|llllll|}
\hline Treatment & $\begin{array}{l}\text { Plant height } \\
(\mathbf{c m})\end{array}$ & $\begin{array}{l}\text { Number of spikes } \\
\left(\times 10^{6} \mathbf{h a}^{-1}\right)\end{array}$ & Number of grains (spike $\left.{ }^{-1}\right)$ & $\begin{array}{l}\text { 1000-grain weight } \\
(\mathbf{g})\end{array}$ & $\begin{array}{l}\text { Grain production } \\
\left(\mathbf{k g ~ h a}^{-1}\right)\end{array}$ \\
\hline Control & $102.27^{\mathrm{a}}$ & $27.15^{\mathrm{a}}$ & $48.00^{\mathrm{a}}$ & $19.85^{\mathrm{c}}$ & $2.76^{\mathrm{b}}$ \\
\hline $\mathrm{T}$ & $106.77^{\mathrm{a}}$ & $26.95^{\mathrm{a}}$ & $49.00^{\mathrm{a}}$ & $22.17^{\mathrm{b}}$ & $2.86^{\mathrm{ab}}$ \\
\hline TS & $104.43^{\mathrm{a}}$ & $27.69^{\mathrm{a}}$ & $50.33^{\mathrm{a}}$ & $23.43^{\mathrm{a}}$ & $3.00^{\mathrm{a}}$ \\
\hline S & $109.73^{\mathrm{a}}$ & $27.04^{\mathrm{a}}$ & $48.67^{\mathrm{a}}$ & $21.73^{\mathrm{bc}}$ & $2.76^{\mathrm{b}}$ \\
\hline
\end{tabular}

\subsection{Effect of Se fertilizer application on Se content in oat plants}

Without Se fertilizer, the maximum Se was accumulated in roots and the minimum in the stem (Table 2). The order of Se accumulation in various organs of oats without Se fertilizer was stem > grain >leaf $>$ ear $>$ root. The Se accumulation in various organs was increased to different degrees after Se application. Among them, soil topdressing $(T)$ significantly increased the Se accumulation in roots, ears, and grains compared with the control, while foliar spray (S) significantly increased the Se contents of stems, leaves, ears, and grains. The combined topdressing + foliar spray (TS) significantly increased the Se content in all parts of the oat plant.

Table 2

Effects of selenium fertilizers on selenium allocation in different organs of oat

\begin{tabular}{|c|c|c|c|c|c|c|c|c|c|c|}
\hline Treatment & $\begin{array}{l}\text { Root } \\
\left(\mu \mathrm{g} \mathrm{kg}{ }^{-}\right. \\
\left.{ }^{1}\right)\end{array}$ & $\begin{array}{l}\% \\
\text { Increase }\end{array}$ & $\begin{array}{l}\text { Stem } \\
\text { ( } \mu \mathrm{g} \mathrm{kg} \\
\text { 1) }\end{array}$ & $\begin{array}{l}\% \\
\text { Increase }\end{array}$ & $\begin{array}{l}\text { Leaf } \\
(\mu g \\
\left.\mathrm{kg}^{-1}\right)\end{array}$ & $\begin{array}{l}\% \\
\text { Increase }\end{array}$ & $\begin{array}{l}\text { Ear } \\
\left(\mu \mathrm{g} \mathrm{kg}{ }^{-}\right. \\
\left.{ }^{1}\right)\end{array}$ & $\begin{array}{l}\% \\
\text { Increase }\end{array}$ & $\begin{array}{l}\text { Grain } \\
(\mu g \\
\left.\mathrm{kg}^{-1}\right)\end{array}$ & $\begin{array}{l}\% \\
\text { Increase }\end{array}$ \\
\hline Control & $132.08^{b}$ & - & $36.18^{c}$ & - & $45.01^{b}$ & - & $98.00^{d}$ & - & $41.72^{d}$ & - \\
\hline $\mathrm{T}$ & $152.27^{a}$ & 15.3 & $47.11^{\mathrm{b}}$ & 30.2 & $52.84^{b}$ & 17.4 & $101.28^{c}$ & 3.35 & $48.27^{c}$ & 15.7 \\
\hline S & $135.24^{b}$ & 2.4 & $56.01^{a}$ & 54.8 & $79.39^{a}$ & 76.4 & $107.86^{b}$ & 10.1 & $53.44^{b}$ & 28.1 \\
\hline TS & $158.15^{\mathrm{a}}$ & 19.7 & $51.59^{a b}$ & 42.6 & $72.10^{a}$ & 60.2 & $125.83^{a}$ & 28.4 & $57.71^{a}$ & 38.3 \\
\hline
\end{tabular}

Note: Different lowercase letters in the same column indicate significant differences among different treatments. $(P<0.05)$. CK: Control, T: soil application, TS: combined soil and foliar application, S: foliar application

The conversion rate of exogenous Se was above $100 \%$ for all Se treatments and all plant organs (Table 3). The conversion rate of exogenous Se under the S treatment followed the order leaf $>$ stem > grain > ear > root; under the T treatment, it followed the order root > stem > leaf > grain > ear; and under the TS treatment, it followed the order ear >leaf > root > grain > stem. Under the S 
treatment, the conversion rate of exogenous Se in leaves reached $644.63 \%$, and the conversion rates in stems, leaves, and grains were higher than those in the other treatments $(P<0.05)$. Under the $T$ treatment, the conversion rate of Se in grains was significantly lower than that under the TS and $S$ treatments. Under the TS treatment, the conversion rate of exogenous Se in leaves was lower than that under the $S$ treatment $(P<0.05)$, and the conversion rates in spikes and grains were slightly improved.

Table 3

Conversion Rate of Exogenous Selenium

\begin{tabular}{|lccccc|}
\hline Treatment & Root (\%) & Stem (\%) & Leaf (\%) & Ear (\%) & Grain (\%) \\
\hline T & $416.00^{\mathrm{a}}$ & $225.21^{\mathrm{b}}$ & $161.33^{\mathrm{c}}$ & $67.58^{\mathrm{c}}$ & $134.96^{\mathrm{b}}$ \\
\hline $\mathrm{TS}$ & $255.92^{\mathrm{b}}$ & $151.28^{\mathrm{c}}$ & $265.94^{\mathrm{b}}$ & $273.20^{\mathrm{a}}$ & $156.97^{\mathrm{b}}$ \\
\hline $\mathrm{S}$ & $59.25^{\mathrm{c}}$ & $371.81^{\mathrm{a}}$ & $644.63^{\mathrm{a}}$ & $184.88^{\mathrm{b}}$ & $219.75^{\mathrm{a}}$ \\
\hline $\begin{array}{l}\text { Note: Different lowercase letters in the same column indicate significant differences among different treatments. }(P<0.05) . \\
\text { T: soil application, TS: combined soil and foliar application, S: foliar application. }\end{array}$ & & \\
\hline
\end{tabular}

\subsection{Effects of Se fertilizer application on soil nutrients, soil enzyme activities, and bacterial community diversity}

The contents of available nitrogen, available potassium, and organic matter in the soil treated with T and TS were significantly increased. However, there were no significant differences in the above indices after Se foliar spray (S). All Se fertilizer

treatments had no significant effect on the content of available phosphorus in the soil. The T and TS can significantly increase the activity of urease, alkaline phosphatase, and sucrase in the soil as compared to the control. There was no significant difference in soil enzyme activities between the control and S. The indices of Chao1, ACE, and Shannon were increased by TS but did not achieve a significant difference, while $T$ and $S$ had no significant effect. 
Effects of selenium fertilizers on nutrients, enzyme activities and diversity of bacterial communities in rhizospheric soil of oat

\begin{tabular}{|c|c|c|c|c|c|}
\hline Indices & & control & $\mathrm{T}$ & TS & $S$ \\
\hline \multirow[t]{4}{*}{ Nutrients } & Available $\mathrm{N}\left(\mathrm{mg} \mathrm{kg}^{-1}\right)$ & $36.66^{b}$ & $38.12^{\mathrm{a}}$ & $38.86^{\mathrm{a}}$ & $36.99^{b}$ \\
\hline & Available- $P\left(\mathrm{mg} \mathrm{kg}^{-1}\right)$ & $5.32^{\mathrm{a}}$ & $5.45^{\mathrm{a}}$ & $5.47^{a}$ & $5.34^{a}$ \\
\hline & Available $-\mathrm{K}\left(\mathrm{mg} \mathrm{kg}^{-1}\right)$ & $74.8^{b}$ & $83.0^{\mathrm{a}}$ & $80.8^{a}$ & $76.3^{\mathrm{b}}$ \\
\hline & $\operatorname{SOM}\left(\mathrm{g} \mathrm{kg}^{-1}\right)$ & $11.03^{\mathrm{b}}$ & $12.50^{\mathrm{a}}$ & $13.01^{\mathrm{a}}$ & $11.46^{\mathrm{b}}$ \\
\hline \multirow[t]{3}{*}{ Enzymes } & Urease $\left(\mathrm{mg} \mathrm{g}^{-1} 24 \mathrm{~h}^{-1}\right)$ & $0.57^{c}$ & $0.78^{b}$ & $0.90^{\mathrm{a}}$ & $0.56^{c}$ \\
\hline & Phosphatase $\left(\mathrm{mg} \mathrm{g}^{-1} 24 \mathrm{~h}^{-1}\right)$ & $3.68^{b}$ & $3.82^{\mathrm{a}}$ & $4.00^{\mathrm{a}}$ & $3.62^{b}$ \\
\hline & Sucrase $\left(\mathrm{mg} \mathrm{g}^{-1} 24 \mathrm{~h}^{-1}\right)$ & $4.58^{b}$ & $5.14^{\mathrm{a}}$ & $4.92^{\mathrm{a}}$ & $4.62^{b}$ \\
\hline \multirow[t]{4}{*}{ Diversity Index } & Chao 1 & $2373^{a b}$ & $2229^{b}$ & $2885^{\mathrm{a}}$ & $1845^{\mathrm{b}}$ \\
\hline & ACE & $2684^{\mathrm{ab}}$ & $2356^{b}$ & $3213^{a}$ & $1994^{\mathrm{b}}$ \\
\hline & Simpson & $0.99^{a}$ & $1.00^{\mathrm{a}}$ & $1.00^{\mathrm{a}}$ & $0.99^{a}$ \\
\hline & Shannon & $9.45^{\mathrm{ab}}$ & $9.98^{a}$ & $10.10^{\mathrm{a}}$ & $9.10^{\mathrm{b}}$ \\
\hline
\end{tabular}

Note: Different lowercase letters in the same column indicate significant differences among different treatments. $(P<0.05)$. CK: Control, T: soil application, TS: combined soil and foliar application, S: foliar application

\subsection{Effect of Se fertilizer application on soil bacterial community composition}

\subsubsection{Bacterial community structure at the phylum and species level}

Under Se treatments, 26 bacterial phyla were identified. The relative abundance of eight phyla was $\geq 0.01$ (dominant bacterial phyla), whereas that of the remaining 18 phyla was $<0.01$. In the cluster analysis of the top 20 phyla (Fig. 1A), CK and S were clustered together, and T and TS were clustered together. The relative abundance of bacteria could be influenced by exogenous Se fertilizer application. The T and TS treatments significantly increased the relative abundance of Bacteroidetes, Proteobacteria, Chloroflexi, and Gemmatimonadetes. In addition, T significantly increased the relative abundance of Acidobacteria; $\mathrm{S}$ increased the relative abundance of Firmicutes.

Under different treatments, 637 bacterial genera were identified. The relative abundance of 19 genera was $\geq 0.01$ (dominant bacterial genus), whereas that of the remaining 618 genera was $<0.01$. The cluster analysis of the top 30 genera (Fig. 1B) revealed that CK and S were clustered together, and T and TS were clustered together. Se application to the soil had a significant effect on bacterial abundance. T treatment significantly increased the relative abundance of Lysobacter, Holophaga, Candidatus Koribacter, Povalibacter, and Pyrinomonas. The TS treatment significantly increased the relative abundance of Aciditeromonas, Gemmatimonas, Geobacter, and Thiobacter. Furthermore, T and TS reduced the relative abundance of Granulicella, Bacillus, Raoultella, Lactococcus, Klebsiella, and Pseudomonas; S increased the relative abundance of Bacillus.

\subsubsection{Correlations between soil bacterial communities and soil nutrients}

The soil microbial communities under the four treatments were analyzed using a PCA (Fig. 2A). The variation in the first principal component (PC1) was mainly caused by soil application of Se, while the variation in the second principal component (PC2) was mainly caused by the foliar application of Se. The contribution rates of PC1 and PC2 were $88.21 \%$ and $9.58 \%$, respectively ( $97.79 \%$ in total). All three Se fertilizer treatments differed significantly from the CK treatment. In Fig. 2A, S and CK 
are both located on the negative side of PC1 with CK on the positive and S on the negative side of PC2. T and TS are both located on the positive side of PC1, with T on the positive and TS on the negative side of PC2. This shows that the method of applying Se fertilizer has a significant effect on the structure of soil microbial communities $(P<0.05)$. Soil application of Se had a greater impact on soil microbial community structure than the foliar application of Se.

The relationship between bacterial community structure at the phylum level and soil nutrients, enzyme activities, and bacterial diversity indices were analyzed using an RDA (Fig. 2B). Soil nutrients and enzyme activities were significantly positively correlated with Actinobacteria, Acidobacteria, Gemmatimonadetes, Bacteroidetes, Planctomycetes, and Chloroflexi, and were significantly negatively correlated with Proteobacteria and Firmicutes. This shows that soil nutrients, enzyme activities, and bacterial communities are closely related, and bacterial communities play an important role in the cycling of soil materials. Soil nutrients have a significant effect on soil microbial communities.

\subsubsection{PICRUSt analysis: Composition of functional gene families}

The predicted functional gene families were compared with the KEGG database (Fig. 3). The functions annotated by all bacterial gene sequences can be divided into three categories related to metabolism, environmental information processing, and genetic information processing. From the metabolism category, the microorganisms involved in carbohydrate and amino acid metabolism were more abundant $(>6 \%)$. Among environmental information processing, the bacteria involved in membrane transport had a significant advantage (>6\%). Among the flora involved in the processing of genetic information, the bacteria involved in replication and repair were the most significant $(>6 \%)$.

A comparison among the four treatments revealed that the topdressing of $\mathrm{Se}$ (T and TS) significantly improved the relative abundance of bacteria involved in amino acid metabolism, replication, repair, and energy metabolism, but had a certain weakening effect on membrane transport. There was no significant difference between foliar spray of Se fertilizer (S) and control treatment (CK).

\section{Discussion}

\subsection{Effects of Se fertilizer application on yield components of oats}

In the present study, a combined application of topdressing and foliar spray (TS) significantly increased oat yield compared to the control. Previous studies have shown that the appropriate amount of soil Se fertilizer promotes oat plant development, increases seed setting rate and crop yield (Escalante-Valdez et al. 2019; Lara et al. 2019; Ligowe et al. 2020; Liu et al. 2020). The increments in yield could be explained by the improvement in seed setting rates and grain weights (Luo et al., 2020). In the present study, the highest grain yield and 1000-grain weight were obtained under the combined soil + foliar (TS) application of Se (Table 1). While the 1000-grain weight was significantly higher for the soil-applied Se (T) than the foliar spray of Se fertilizer (S). The grain weight is the main determining yield determining traits that had a linear correlation with grain yield. The higher net photosynthetic rate during the grain filling stage produced heavier grains because the amount of net photosynthesis has a decisive effect on the seed setting rate and grain weight (Luo et al., 2020).

This might be because Se can affect the synthesis of chlorophyll in plants and regulate the electron transfer in photosynthesis and respiration, and thus increase the photosynthetic capacity and yield of crops (Zhang et al. 2014b). In addition, Se fertilizer can promote the growth of oats by increasing the absorption of mineral elements (Lopes et al. 2017; Rayman 2008) and activity of superoxide dismutase and peroxidase, while reducing senescence and improve anti-aging by reducing lipid peroxidation and free proline in leaves (Jozwiak \&Politycka 2019). At the same time, the booting stage is an important period for the reproductive growth of oats. The application of organic Se fertilizer in the soil not only supplements Se but also improves organic matter in the soil. Therefore, single soil application of Se fertilizer is better than the single foliar spray of Se, and soil application + foliar spray application is better than soil application or foliar application.

\subsection{Effect of Se fertilizer application on the distribution of Se in oats and the conversion rate of exogenous Se}


The Se content in oat plants was always the highest in the roots and lowest in the stems in this study irrespective of the application method (soil or foliar) of organic Se. The effect of topdressing of organic Se fertilizer on the Se content of oat roots was more prominent than that of foliar spray. Foliar spray of Se fertilizer mainly affected the Se content of plant stems, leaves, spikes, and grains. The plant root system absorbs $\mathrm{Se}$ in the form of selenite $\left(\mathrm{SeO}_{3}{ }^{2-}\right)$ and then Se is converted to insoluble selenomethionine (Sors et al. 2005). While Se absorbed through the foliar spray is easily carried through the vascular system without a long process of soil fixation, root absorption, and transportation to stems and leaves, thereby increasing the effectiveness of Se. The total Se content was highest by the soil + foliar application of Se (TS), followed by foliar spray of Se $(S)$, and the lowest by soil application $(T)$. These results indicate that the foliar spray of Se fertilizer is more beneficial for the accumulation of Se in grains than the soil application. At the same time, there is an additive effect of the combined soil and foliar application of Se on the Se accumulation in oat grains. The present study also showed that the application of exogenous Se increased the uptake of Se from the soil by oat roots. The low recovery efficiency of exogenous Se in grains by the soil treatment (T) and high accumulation of Se in leaves by foliar spray (S) can be improved by soil + foliar treatment of Se (TS).

\subsection{Effects of Se fertilizer application on soil nutrients and soil bacterial communities}

The topdressing of Se and topdressing + foliar application significantly increased the nutrient content, soil organic matter, and activities of urease, phosphatase, and sucrase in soil. This may be because the organic Se fertilizer provides some carbon, nitrogen sources, and Se for the microorganisms. Meanwhile, organic matter can protect the soil sucrose from decomposition and denaturation. In addition, soil enzymes are produced by the metabolism of soil microorganisms, while organic Se fertilizer can improve the metabolism of soil microorganisms, so the activities of soil urease, sucrase, and alkaline phosphatase are improved.

The diversity and richness of soil bacterial community composition is an important indicator to measure the stability and health of the soil ecosystem (Geisseler et al. 2017; Panico et al. 2018). The Se in the soil changes the cell metabolism and microbial function of soil microorganisms, causing changes in the survival and competitiveness of microorganisms and resulting in changes in population diversity (Wang et al. 2018). Gonzalez-Gil et al. (2016) reported changes in the microbial community structure after $21 \mathrm{~d}$ exposure of selenite. The Se in soil could increase the diversity of Se reducing or oxidizing bacteria. The Se reducing bacteria play a pivotal role in the Se cycle in the environment. Bacteria can reduce soluble selenate and selenite to elemental Se and soluble selenide. Selenide and elemental Se oxidized back to selenite or selenate by seleniumoxidizing bacteria (Nancharaiah and Lens, 2015).

In the present study, the topdressing of Se organic fertilizers (TS) increased the diversity indices (Chao1, ACE, and Shannon) of the bacterial community in the soil. This may be related to the changes in soil nutrients after the application of Se organic fertilizer. The content of $\mathrm{N}, \mathrm{K}$, and organic matter in the soil increased significantly after the application of Se fertilizer, which accelerated the activities of the bacterial community in the soil (Dong et al. 2014; Zhang et al. 2016), and also increased the activity of urease, alkaline phosphatase, and sucrose in soil.

From the PCA analysis, it can be seen that the soil + foliar application of Se fertilizer significantly affected the soil microbial community structure and increased Proteobacteria, Bacteroidetes, Acidobacteria, and other microbial groups involved in the decomposition of organic matter in the soil, providing more carbon and nitrogen sources for microbial activities in the soil (Fierer et al. 2012; Wessén et al. 2010). Besides, soil Se fertilizer (T and TS) significantly increased the relative abundance of Bacteroidetes, Proteobacteria, Chloroflexi, and Gemmatimonadetes. These bacteria are closely associated with the content of soil nutrients, and their relative abundance can reflect the level of soil nutrients. Proteobacteria and Bacteroides inhabit nutrient-rich conditions, and their relative abundance increases at high organic matter levels. Proteobacteria are metabolically versatile gram-negative microorganisms that reduce selenate and selenite (Gonzalez-Gil et al. 2016). Bacteroides members have a phosphorus-dissolving effect, and they were positively correlated with the content of available phosphorus (Fig. 2A) (Fierer et al. 2012). Some Chloroflexi members are autotrophic bacteria that can decompose organic matter and use 3hydroxypropionic acid to fix $\mathrm{CO}_{2}$ to produce energy. Therefore, they can survive in environments with different levels of nutrition. Chloroflexi members are more abundant under higher nutrient conditions (Boyle-Yarwood et al. 2008). These findings

Page $10 / 18$ 
show that Chloroflexi members are more inclined to live in an environment with adequate nutrition. This is similar to the results of a previous study (Zhao et al. 2020). At the genus level, T treatment increased the abundance of Lysobacter, Holophaga, Candidatus-Koribacter, Povalibacter, and Pyrinomonas. TS treatment increased the relative abundance of Gemmatimonas, Geobacter, and Thiobacter. T and TS decreased the abundance of Granulicella, Bacillus, Raoultella, Lactococcus, and Klebsiella, while increased the abundance of Pseudomonas. Gonzalez-Gil et al. (2016) reported that about $90 \%$ of the Pseudomonadacea of the selenite reducing granules belonged to the genus Pseudomonas. The presence of Pseudomonas is of particular interest because most of the members of this family are aerobic. Pseudomonas might be distinctly highly tolerant to Se and selenite (Ye et al. 2020). Overall, these results showed that Se fertilizer application to soil had a significant effect on the structure of the soil microbial community.

Until now, only a few bacterial genes involved in Se utilization had been identified. The most abundant gene sequences of soil microbes were mainly related to metabolism, environmental information processing, and genetic information processing. Among all flora involved in major metabolic functions, those involved in carbohydrate metabolism, amino acid metabolism, membrane transport, replication, and repair have significant advantages. The soil application of Se fertilizer significantly improved the abundance of bacteria involved in amino acid metabolism, replication and repair, and energy metabolism, which further confirmed that the soil application of Se fertilizer is beneficial for the metabolism of soil bacteria.

\section{Conclusions}

The topsoil application of organic Se fertilizer or the foliar spray of Se fertilizer increased the grain yield of oats and the Se content in the grains. On the whole, the foliar spray of Se fertilizer had no significant effect on soil nutrients and soil microbial communities. Topdressing of organic Se fertilizer is conducive to increasing the $\mathrm{C}$ and $\mathrm{N}$ nutrients in the soil by increasing the diversity and richness of the microbial communities of oat rhizosphere soil and the expression of related genes. The combined soil and foliar application of Se fertilizer proved more advantageous than the single soil or foliar application of Se for increasing yield and Se content in oat grains.

\section{Declarations}

\section{Ethics approval and consent to participate}

Not applicable

\section{Consent for publication}

Not applicable

\section{Availability of data and materials}

The data supporting the findings of this study are available within the supplementary information file named "Supplementary Information of Figures"

\section{Competing interests}

The authors declare that they have no competing interests.

\section{Funding}

This study was financially supported by the Special Plan of Scientific Research for the Shanxi Agriculture Valley of China (SXNGJSKYZX 201701), the Key Project of the Shanxi Key R \& D Program of China (201703D211001-02), the "1331 Project" of the Crop Ecology and Dry Cultivation Physiology Key Laboratory of Shanxi Province (201705D111007, [2017]14), and the Shanxi Collaborative Innovation Centre with Featured Crops: High-quality and Efficiency Production in Loess Plateau ([2016]5). 


\section{Authors' contributions}

All authors contributed to the study conception and design. Overall experimental design and field planning were performed by Yang Zhenping, Gao Zhiqiang, Guo Anna, and Li Junhui. Field sampling and survey indicators was performed by Li Junhui, Yang Wenping, Guo Anna, Yang Sheng, and Wang Kai. Data collection and analysis were performed by Li Junhui, Yang Wenping, Chen Jie, Qiao Yuejing, and Wang Jianwu. Language technology service: Sumera Anwar. The first draft was written by Li Junhui and all authors commented on previous versions of the manuscript. The review and editing of the previous versions of the manuscript was performed by Yang Zhenping. All authors read and approved the final manuscript.

\section{References}

Bakker MG, Chaparro JM, Manter DK, \& Vivanco JM. (2015): Impacts of bulk soil microbial community structure on rhizosphere microbiomes of Zea mays. Plant and Soil, 392(1), 115-126.

Banuelos G, Lin Z-Q, Moraes M, Guilherme L, Reis A (2015): Global advances in selenium research from theory to application. Proceedings of the 4th International Conference on Selenium in the Environment and Human Health 2015). Global predictions of selenium distributions in soils.

Bell T, Newman JA, Silverman BW, Turner SL, Lilley AK (2005): The contribution of species richness and composition to bacterial services. Nature 436, 1157-60

Boyle-Yarwood SA, Bottomley PJ, Myrold DD (2008): Community composition of ammonia-oxidizing bacteria and archaea in soils under stands of red alder and Douglas fir in Oregon. Environmental Microbiology 10, 2956-2965

Brown KM, Arthur JR (2001): Selenium, selenoproteins and human health: A review. Public Health Nutrition 4, 593-9

Chen LC, Yang FM, Xu J, Hu Y, Hu QH, Zhang YL, Pan GX (2002): Determination of selenium concentration of rice in China and effect of fertilization of selenite and selenate on selenium content of rice. Journal of Agricultural and Food Chemistry 50, 51285130

Ding Y, Wang Y, Zheng X, Cheng W, Shi R, Feng R (2017): Effects of foliar dressing of selenite and silicate alone or combined with different soil ameliorants on the accumulation of As and $\mathrm{Cd}$ and antioxidant system in Brassica campestris.

Ecotoxicology and Environmental Safety 142, 207-215

Dinh QT, Cui Z, Huang J, Tran TAT, Wang D, Yang W, Zhou F, Wang M, Yu D, Liang D (2018): Selenium distribution in the Chinese environment and its relationship with human health: A review. Environment International 112, 294-309

Dong W-Y, Zhang X-Y, Dai X-Q, Fu X-L, Yang F-T, Liu X-Y, Sun X-M, Wen X-F, Schaeffer S (2014): Changes in soil microbial community composition in response to fertilization of paddy soils in subtropical China. Applied Soil Ecology 84, 140-147

Escalante-Valdez MJ, Guardado-Felix D, Serna-Saldivar SO, Barrera-Arellano D, Chuck-Hernandez C (2019): Effects of post anthesis foliar application of sodium selenite to soybeans (Glycinemax): Lipid composition and oil stability. Biomolecules 9 , 772

Fang Y, Wang L, Xin Z, Zhao L, An X, Hu Q (2008): Effect of foliar application of zinc, selenium, and iron fertilizers on nutrients concentration and yield of rice grain in China. Journal of Agricultural and Food Chemistry 56, 2079-84

Feng S, Zhang H, Wang Y, Bai Z, Zhuang G (2009): Analysis of fungal community structure in the soil of Zoige Alpine Wetland. Acta Ecologica Sinica 29, 260-266

Fierer N, Lauber CL, Ramirez KS, Zaneveld J, Bradford MA, Knight R (2012): Comparative metagenomic, phylogenetic and physiological analyses of soil microbial communities across nitrogen gradients. The ISME Journal 6, 1007-17

Page 12/18 
Gonzalez-Gil G, Lens PN, Saikaly PE (2016): Selenite reduction by anaerobic microbial aggregates: microbial community structure, and proteins associated to the produced selenium spheres. Frontiers in Microbiology 7, 571

Gao Y, Liang J, Xiao R, Zang P, \& Zhang L (2018). Effect of four trace elements on Paenibacillus polymyxa proliferation, activity, and colonization in ginseng. AMB Express, 8, 1 -7250

Geisseler D, Linquist BA, Lazicki PA (2017): Effect of fertilization on soil microorganisms in paddy rice systems: A metaanalysis. Soil Biology and Biochemistry 115, 452-460

Golebiewski M, Deja-Sikora E, Cichosz M, Tretyn A, \& Wrobel, B (2014). 16s rDNA pyrosequencing analysis of bacterial community in heavy metals polluted soils. Microbial Ecology.

Golubkina N, Skriabin K (2010): Anomalous accumulation of selenium by genetically modified potato, stable to Colorado beetle. Journal of Food Composition and Analysis 23, 190-193

Guan SY (1986): Soil enzymes and its research methods. China Agriculture Press, Beijing, pp 274-339

Jozwiak W, Politycka B (2019): Effect of selenium on alleviating oxidative stress caused by a water deficit in cucumber roots. Plants 8, 217

Kieliszek M, Blazejak S (2013): Selenium: Significance, and outlook for supplementation. Nutrition 29, 713-8

Lara TS, de Lima Lessa JH, Dazio de Souza KR, Branco Corguinha AP, Dias Martins FA, Lopes G, Guimaraes Guilherme LR (2019): Selenium biofortification of wheat grain via foliar application and its effect on plant metabolism. Journal of Food Composition and Analysis 81, 10-18

Lareen A, Burton F, \& Schäfer P (2016): Plant root-microbe communication in shaping root microbiomes. Plant Molecular Biology, 90(6), 575-587.

Li X, Meng D, Li J, Yin H, Liu H, Liu X, \& Yan, M. (2017). Response of soil microbial communities and microbial interactions to long-term heavy metal contamination. Environmental Pollution, 231, 908-917.

Ligowe IS, Young SD, Ander EL, Kabambe V, Chilimba ADC, Bailey EH, Lark RM, Nalivata PC (2020): Selenium biofortification of crops on a Malawi Alfisol under conservation agriculture. Geoderma 369, 114315

Liu F, Hewezi T, Lebeis SL, Pantalone V, Grewal PS, \& Staton ME (2019). Soil indigenous microbiome and plant genotypes cooperatively modify soybean rhizosphere microbiome assembly. BMC Microbiology, 19(1), 1-19

Liu X, Huang Z, Li Y, Xie W, Li W, Tang X, Ashraf U, Kong L, Wu L, Wang S, Mo Z (2020): Selenium-silicon (Se-Si) induced modulations in physio-biochemical responses, grain yield, quality, aroma formation and lodging in fragrant rice. Ecotoxicology and Environmental Safety 196, 110525

Longchamp M, Castrec-Rouelle M, Biron P, Bariac T (2015): Variations in the accumulation, localization, and rate of metabolization of selenium in mature Zea mays plants supplied with selenite or selenate. Food Chemistry 182, 128-135

Lopes G, Ávila FW, Guilherme LRG (2017): Selenium behavior in the soil environment and its implication for human health. Ciência e Agrotecnologia 41, 605-615

Lozupone C, Knight R (2005): UniFrac: A new phylogenetic method for comparing microbial communities. Applied and Environmental Microbiology 71, 8228-35

Lozupone CA, Hamady M, Kelley ST, Knight R (2007): Quantitative and qualitative beta diversity measures lead to different insights into factors that structure microbial communities. Applied and Environmental Microbiology 73, 1576-85

Page 13/18 
Luo H, He L, Du B, Pan S, Mo Z, Duan M, Tian H, Tang X (2020): Biofortification with chelating selenium in fragrant rice: Effects on photosynthetic rates, aroma, grain quality and yield formation. Field Crops Research 255, p.107909.

Doi.org/10.1016/j.fcr.2020.107909.

Manojlovic MS, Loncaric Z, Cabilovski RR, Popovic B, Karalic K, Ivezic V, Ademi A, Singh BR (2019): Biofortification of wheat cultivars with selenium. Acta Agriculturae Scandinavica Section B-Soil and Plant Science 69, 715-724

Mendes, R., Kruijt, M., De Bruijn, I., Dekkers, E., van der Voort, M., Schneider, J. H., ... \& Raaijmakers, J. M. (2011). Deciphering the rhizosphere microbiome for disease-suppressive bacteria. Science, 332(6033), 1097-1100

Muller AK, Westergaard K, Christensen S, Sorensen SJ (2002): The diversity and function of soil microbial communities exposed to different disturbances. Microbial Ecology 44, 49-58

Nacke H, Thürmer A, Wollherr A, Will C, Hodac L, Herold N, \& Daniel R. (2011): Pyrosequencing-based assessment of bacterial community structure along different management types in German forest and grassland soils. PloS one, 6(2), e17000

Nancharaiah YV, Lens PNL (2015): Ecology and biotechnology of selenium-respiring bacteria. Microbiology and Molecular Biology Reviews, 79(10), 61-80. doi:10.1128/MMBR.00037-14

Palomo A, Jane Fowler S, Gulay A, Rasmussen S, Sicheritz-Ponten T, Smets BF (2016): Metagenomic analysis of rapid gravity sand filter microbial communities suggests novel physiology of Nitrospira spp. The ISME Journal 10, 2569-2581

Pająk M, Błońska E, Frąc M, \& Oszust K. (2016). Functional diversity and microbial activity of forest soils that are heavily contaminated by lead and zinc. Water, Air, \& Soil Pollution, 227(9), 1-14

Panico SC, Memoli V, Esposito F, Maisto G, De Marco A (2018): Plant cover and management practices as drivers of soil quality. Applied Soil Ecology 129, 34-42

Ramette A (2007): Multivariate analyses in microbial ecology. FEMS Microbiology Ecology 62, 142-60

Rayman MP (2008): Food-chain selenium and human health: Emphasis on intake. British Journal of Nutrition 100, 254-68

Reis HPG, de Queiroz Barcelos JP, Silva VM, Santos EF, Tavanti RFR, Putti FF, Young SD, Broadley MR, White PJ, Dos Reis AR (2020): Agronomic biofortification with selenium impacts storage proteins in grains of upland rice. Journal of the Science of Food and Agriculture 100, 1990-1997

Rivera-Martin A, Broadley MR, Poblaciones MJ (2020): Soil and foliar zinc application to biofortify broccoli (Brassica oleracea var. italica L.): Effects on the zinc concentration and bioavailability. Plant, Soil and Environment 66, 113-118

Rosenfeld CE, James BR, Santelli CM (2018): Persistent bacterial and fungal community shifts exhibited in seleniumcontaminated reclaimed mine soils. Applied and Environmental Microbiology 84, 1394

Schloss PD, Handelsman J (2005): Introducing DOTUR, a computer program for defining operational taxonomic units and estimating species richness. Applied and Environmental Microbiology 71, 1501-1506

Schloss PD, Gevers D, Westcott SL (2011): Reducing the effects of PCR amplification and sequencing artifacts on 16S rRNAbased studies. Plos One 6, e27310

Shi Y-J, Shi Y-J, Wang Y-R, Li T-C, Zhou B-C, Xie Y, Xu F-Y, Liang R-Y (2018): Dynamic responses of soil enzymes to exogenous sodium selenite and selenomethionine. Acta Scientiae Circumstantiae 38, 1189-1196

Song J, Shen Q, Shi J, Xu J, Brookes PC, \& Liu X (2020). Changes in microbial community structure due to chronic trace element concentrations in different sizes of soil aggregates. Environmental Pollution, 268, 115933

Page $14 / 18$ 
Sors TG, Ellis DR, Salt DE (2005): Selenium uptake, translocation, assimilation, and metabolic fate in plants. Photosynthesis Research 86, 373-89

Talbot JM, Bruns TD, Smith DP, Branco S, Glassman SI, Erlandson S, Vilgalys R, Peay KG (2013): Independent roles of ectomycorrhizal and saprotrophic communities in soil organic matter decomposition. Soil Biology and Biochemistry 57, 282291

Wang D, Zhou F, Yang WX, Peng Q, Man N, Liang DL (2017): Selenate redistribution during aging in different Chinese soils and the dominant influential factors. Chemosphere 182, 284-292

Wang D, Dinh QT, Thu TTA, Zhou F, Yang WX, Wang MK, Song WW, Liang DL (2018): Effect of selenium-enriched organic material amendment on selenium fraction transformation and bioavailability in soil. Chemosphere 199, 417-426

Wessén E, Hallin S, Philippot L (2010): Differential responses of bacterial and archaeal groups at high taxonomical ranks to soil management. Soil Biology and Biochemistry 42, 1759-1765

Ye Y, Qu J, Pu Y, Rao S, Xu F, Wu C (2020): Selenium Biofortification of Crop Food by Beneficial Microorganisms. Journal of Fungi 6(2), p.59.

Zhang LH, Hu B, Li W, Che RH, Deng K, Li H, Yu FY, Ling HQ, Li YJ, Chu CC (2014b): OsPT2, a phosphate transporter, is involved in the active uptake of selenite in rice. New Phytologist 201, 1183-1191

Zhang Q, Liang G, Zhou W, Sun J, Wang X, He P (2016): Fatty-acid profiles and enzyme activities in soil particle-size fractions under long-term fertilization. Soil Science Society of America Journal 80, 97-111

Zhang Z-P, Tao G-X, Yi S-J, Mao X (2019): Compressive mechanical property test and crack formation law analysis of naked oats grain. Journal of Shenyang Agricultural University 50, 371-377

Zhao L-J, Liu Y-G, Wang Y, Zhao R, Ren W, Xu M-Z (2020): Bacterial community structure and diversity of sediments in a typical plateau lakeshore. Microbiology China 47(2), 401-410

\section{Figures}



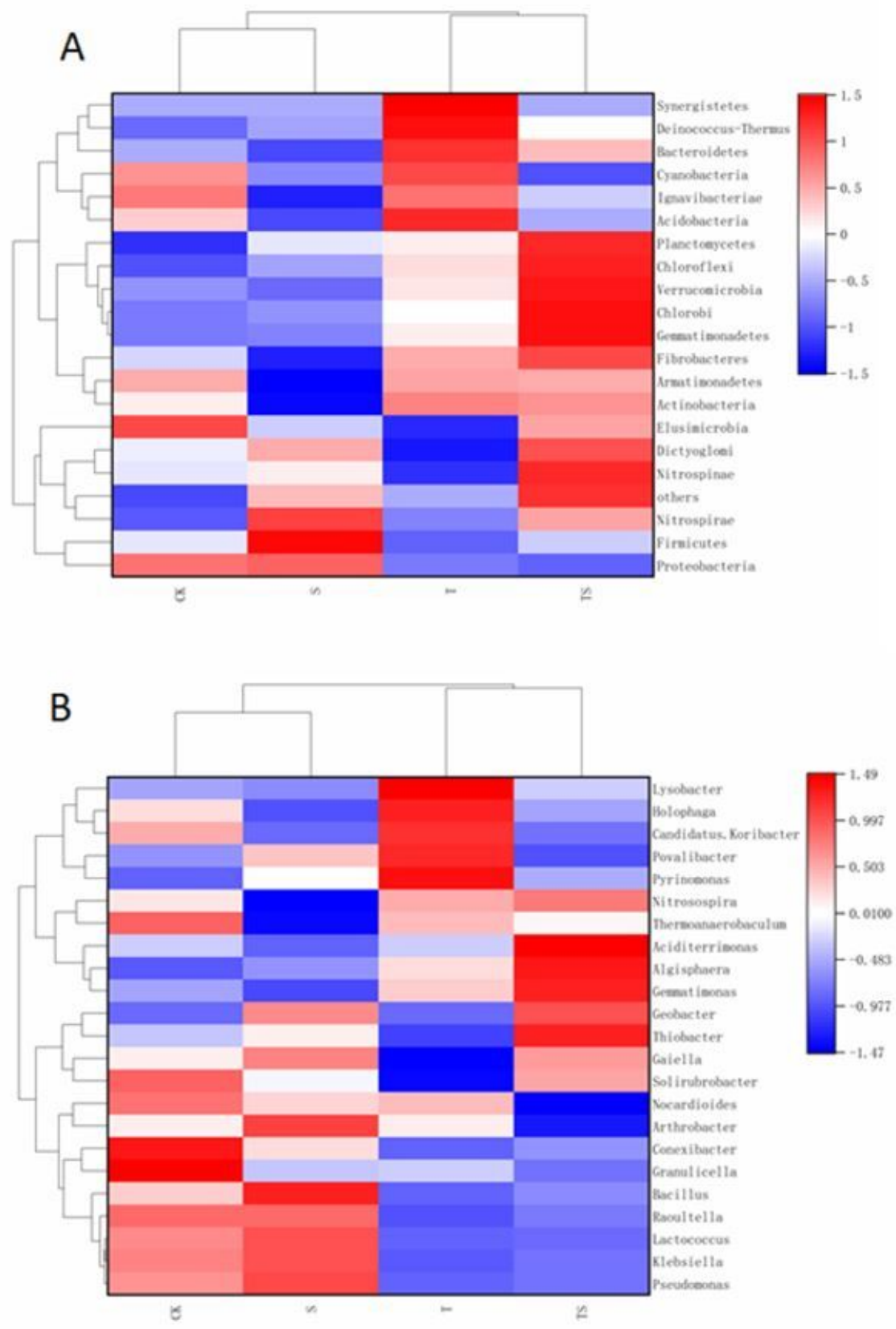

\section{Figure 1}

Relative abundance of the dominant bacterial phyla(A) and the dominant bacterial genera (B) under different selenium treatments. Note: CK: Control, T: soil application, TS: combined soil and foliar application, S: foliar application 

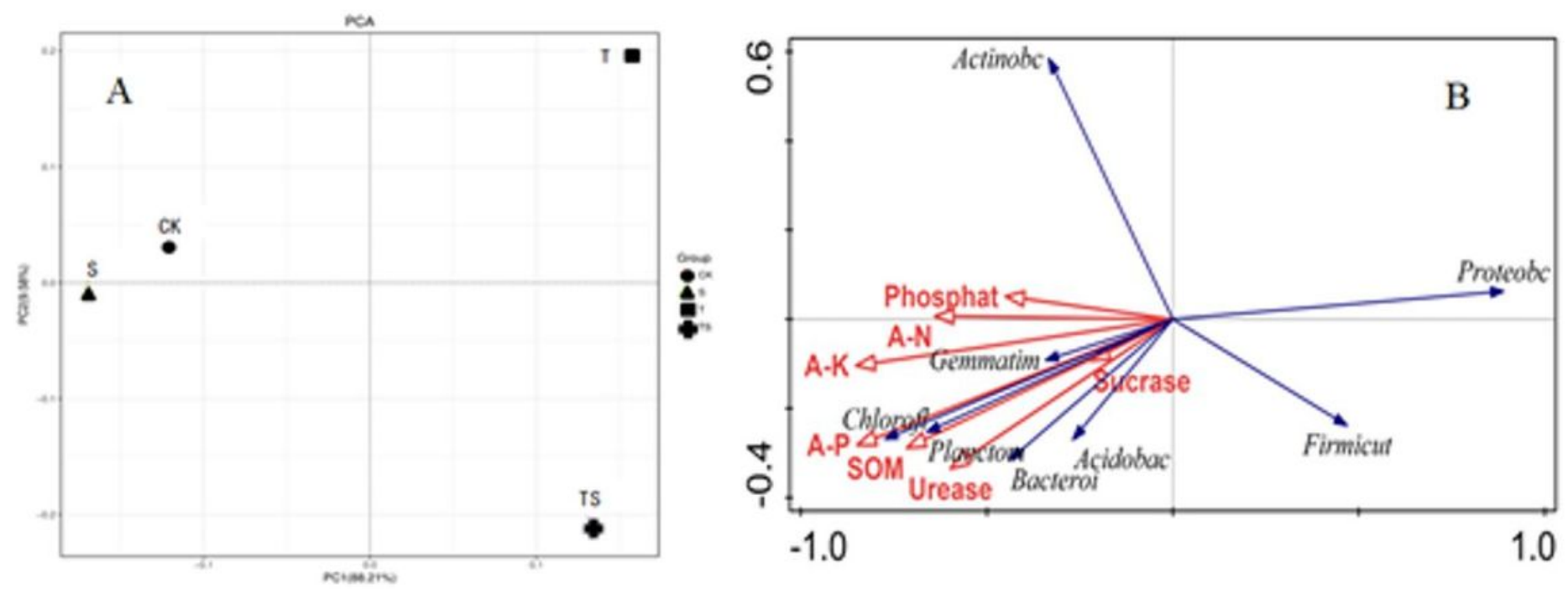

Figure 2

A: Principal component analysis of the soil microbial community under different selenium fertilizer treatments. 2B: Redundancy analysis of the soil bacterial community at the phyla level with soil nutrients, enzyme activities, and bacterial diversity indices. Note: CK: Control, T: soil application, TS: combined soil and foliar application, S: foliar application.

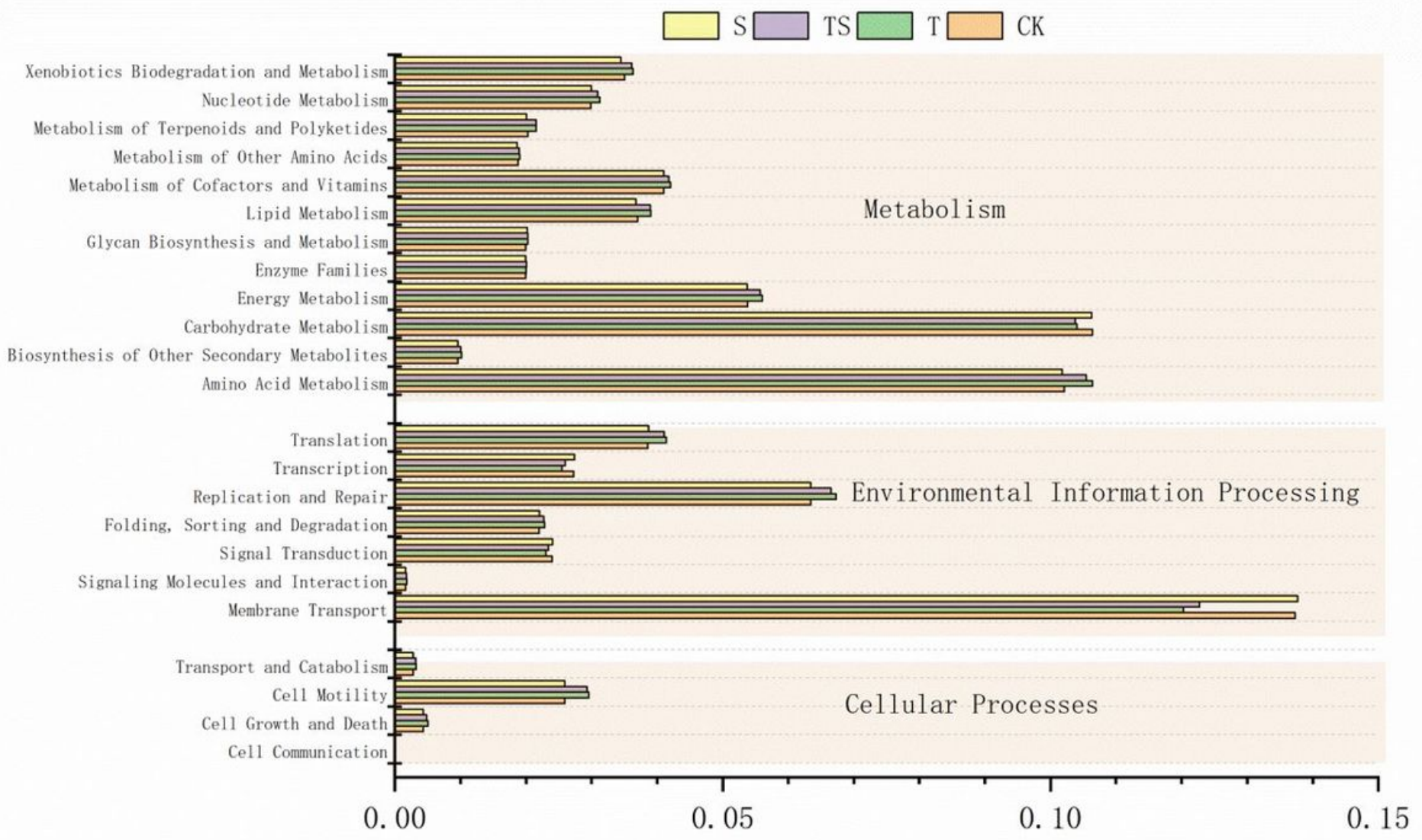

\section{Figure 3}

The relative abundance of KEGG functional genes under different selenium application treatments. Note: CK: Control, T: soil application, TS: combined soil and foliar application, S: foliar application. 


\section{Supplementary Files}

This is a list of supplementary files associated with this preprint. Click to download.

- Responsetocomments.docx 